\title{
AS EMENDAS CONSTITUCIONAIS 95/2016, 106/2020 E 109/2021: Inter- relações com o endividamento público e as políticas sociais
}

\section{THE CONSTITUTIONAL AMENDMENTS 95/2016, 106/2020 AND 109/2021: Interrelations with public debt and social politics}

Cleidijane Siqueira Santos ${ }^{1}$

UFAL: https://orcid.org/0000-0002-9701-6118

João Bosco Araújo da Costa ${ }^{2}$

UFRN: https://orcid.org/0000-0003-4421-728X

DOI: 10.21680/1982-1662.2021v4n31ID25685

\section{Resumo}

Este artigo objetiva refletir sobre a aprovação das Emendas Constitucionais 95/2016, 106/2020 e 109/2021 e suas relações com o aumento do endividamento público por meio da adoção de medidas, que beneficiam o mercado financeiro em detrimento do atendimento das necessidades da população. A primeira emenda instituiu um novo regime fiscal por meio do congelamento das despesas primarias em termos reais por vinte anos; as duas últimas foram aprovadas devido ao estado de calamidade pública decretado em 2020 e 2021 em decorrência da pandemia do Coronavírus. A partir da pesquisa qualitativa, bibliográfica e descritiva verifica-se que as medidas adotadas promovem a elevação do endividamento público, mas esse não se traduz em ações que

\footnotetext{
${ }^{1}$ E-mail: cleidijane@hotmail.com
}

2 E-mail: joaobac58@gmail.com 
beneficiem a população mais pobre, que arca com os custos do endividamento no presente e também no futuro.

Palavras Chave: Emendas Constitucionais. Endividamento público. Políticas Sociais.

\begin{abstract}
This paper discuss about the approval of Constitutional Amendments 95/2016, $106 / 2020$ and 109/2021 and their relationship with the increase in public indebtedness through the adoption of measures that benefit the financial market at the expense of meeting the needs of the population. The First Amendment instituted a new fiscal regime by freezing primary expenditures in real terms for twenty years; the last two were approved due to the state of public calamity decreed in 2020 and 2021 as a result of the Coronavirus pandemic. Using the qualitative, bibliographical and descriptive research, it appears that the measures adopted promote the increase in public indebtedness, but this does not translate into actions that benefit the poorest population, who sustains the costs of indebtedness in the present and also in the future.
\end{abstract}

Keywords: Constitutional Amendments. Public debt. Social politics.

Introdução

As sociedades contemporâneas, em sua maioria, se caracterizam pela existência da diversidade e pluralidade em sua estruturação e reprodução social, as quais expressam assimetrias e conflitos nas esferas do econômico, do social, do político e da cultura. Essas assimetrias de classe, gênero, raça, etnia, geração, categorias dentre outros segmentos sociais, se constituem em agentes e atores, que, a partir de interesses divergentes, disputam os bens materiais e simbólicos arbitrados pelo Estado.

Nesse sentido, onde o Estado vai utilizar os recursos públicos, o que vai definir com que vai gastar e como vai gastar e quem se beneficiará dessa destinação, 
depende da correlação de forças entre os atores políticos, os quais demandarão aos gestores públicos a destinação dos recursos para diversas políticas públicas.

Portanto, o orçamento e a decisão de investir ou deixar de investir em determinada pauta e ou política pública é uma decisão política que atende a um ou mais desses atores que compõe a arena política. Ou seja, a sociedade é formada por indivíduos, grupos e segmentos com interesses diversos e conflitantes, assim, o Estado tem como principal função "[...] arbitrar e compatibilizar as disputas, construindo pontos de convergência e concertação adequados para estabilizar o processo, mantendo, assim, a organização política da sociedade". (CHIAPPIN; LEISTER; CASSETARI JUNIOR, 2019, p.67).

Nesse contexto, as políticas públicas, entendidas aqui como o governo em ação, são fundamentais para a organização desta, através de normas e ações que visem o atendimento de suas demandas e são sempre escolhas políticas, pois o Estado não é um arbitro neutro e os gestores não são despossuídos de opções e vontades políticas a favor de alguns segmentos em detrimento de outros.

O Estado moderno conheceu diversas fases em seu desenvolvimento histórico e a sua atual formatação responde a ampliação de sua intervenção, de um momento em que "cuidava" apenas da segurança e fronteiras para um Estado que atua em todas as esferas da vida social como instância de regulação da sociedade e ator das políticas de regulação, distribuição e redistribuição. Assim, o papel do poder público, através das políticas públicas, é essencial para o desenvolvimento entendido como expansão das capacidades e das liberdades dos indivíduos (SEN, 2010).

Dessa forma, a criação e implementação de políticas distributivas e redistributivas é fundamental no Brasil, devido a uma enorme e histórica desigualdade social, que foi acentuada nos últimos anos em decorrência das crises política e econômica a partir de 2014, e, mais recentemente, a crise sanitária com a pandemia do coronavírus ${ }^{3}$.

No Brasil os direitos sociais como educação, saúde, previdência social dentre outros tornaram-se obrigação do Estado a partir de 1988 com a promulgação da Constituição Federal, porém só a partir do ano 2000 teve-se uma maior preocupação com as políticas sociais, que, após o ano de 2014, começaram a sofrer diversos cortes, oriundos das políticas de contenção de gastos do governo.

\footnotetext{
${ }^{3}$ O primeiro caso de Corona Vírus registrado no país foi em fevereiro de 2020.
} 
Nesse contexto, este trabalho tem como objetivo principal refletir sobre a aprovação das Emendas Constitucionais 95/2016, 106/2020 e 109/2021 e suas relações com o endividamento público recente, em detrimento do investimento em políticas de recorte social, a partir de uma descrição das medidas adotadas nessas emendas, seus impactos no investimento em políticas sociais e no aumento do endividamento público. Para tanto, utilizamos a pesquisa exploratória e qualitativa de caráter descritivo e reflexivo, desenvolvida por meio de revisão bibliográfica e da análise documental das emendas constitucionais citadas.

Para uma melhor sistematização, além dessa breve introdução, dividimos esse três partes: a primeira seção consiste em uma discussão sobre as políticas públicas e as políticas sociais no contexto brasileiro, apresentando algumas classificações discutidas na literatura específica, e contextualizando as políticas sociais no Brasil; a segunda seção apresenta uma descrição reflexiva acerca das Emendas Constitucionais 95/2016, 106/2020 e 109/2021, buscando relacionar suas aprovações com o aumento do endividamento público; por fim, temos as considerações finais do trabalho, que evidenciam a falta de capacidade do governo em alocar os custos, oriundos da pandemia, por toda a sociedade, de maneira que estes não afetem apenas a população mais carente dependente dos serviços públicos, os quais ficarão cada vez mais escassos devido ao elevado endividamento do país. Além disso, algumas medidas incluídas nessas emendas indicam uma proteção ao mercado financeiro por meio do aumento do endividamento público.

\section{Políticas Públicas e Políticas Sociais no Contexto Brasileiro}

As políticas públicas são diversas, “[...] este abanico es tan extenso que va desde la redacción de la Constitución de un país hasta las campañas de comunicación televisivas, pasando por la fijación de impuestos, la educación, la fuerza”. (MENY; THOENIG, 1992, P. 100). A ação a ser empreendida dependerá da conjuntura e problema que ela se prestará a solucionar, daí a importância de compreendermos a classificação destas segundo a literatura específica.

Inicialmente, poderíamos classificá-las em políticas sociais e econômicas. As primeiras visam atender as demandas da sociedade de uma forma "mais direta", buscando solucionar ou amenizar problemas públicos, com o intuito de melhorar a 
qualidade de vida das pessoas. Como exemplo, temos os programas de habitação, educação, serviços médicos, assistência social dentre outros. As políticas econômicas têm como intuito regular à atividade econômica, são as políticas fiscais (tratam das questões relacionadas a arrecadação e gastos governamentais); as monetárias (visam controlar a oferta de moeda na economia); as cambiais (buscam o controle da taxa de câmbio) e as políticas de rendas (intervenção no processo de formação de preços e salários). Boschetti (2009, p.10) afirma que "não se pode explicar a gênese e desenvolvimento das políticas sociais sem compreender sua articulação com a política econômica". Para autora, é fundamental a análise de dados que resultam da política econômica adotada, como: taxas de juros; índices de inflação; taxas de importação e exportação; distribuição do PIB nos orçamentos das políticas dentre outros, objetivando verificar seus efeitos na formação das políticas sociais (BOSCHETTI, 2009).

Ainda sobre a classificação das políticas públicas, Meny e Thoening (1992) mencionam que as classificações mais utilizadas são as que consideram a ação pública função da teoria da mudança social. Nesse sentido, os autores consideram o modelo apresentado por Theodor Lowi, nos anos 60 e 70, o mais completo, pois, “[...] se acuña em un parámetro: la naturaleza de la coerción que una política pública introduce entre el Estado y el sujeto". (MENY; THOENING, 1992, p.101).

Para esses autores, as políticas públicas são classificadas a partir da coerção direta e da coerção indireta, tendo-se, assim: as políticas regulamentárias ou regulatórias e as políticas redistributivas, como resultado do exercício da coerção direta pelo Estado, e as políticas distributivas e constitutivas, como resultado da coerção indireta. Vale salientar que as políticas sociais e econômicas, mencionadas anteriormente, são abarcadas nessa classificação, podendo afetar direta ou indiretamente os comportamentos dos indivíduos.

Na mesma direção, pensando a política pública pela perspectiva do "Estado em Ação", tem-se os trabalhos de Souza (2016) e Souza (2006), os quais estão baseados também no modelo de Theodor Lowi, fundamentados na máxima de que "a política pública faz a política (SOUZA, 2006 p.09). Nessa perspectiva apresentamos aqui, de forma sucinta, as definições desses tipos de política segundo os autores mencionados:

1- Distributivas: referem-se as decisões que beneficiam diretamente determinados grupos ou regiões, e os impactos gerados seriam mais 
individuais que coletivos, outra característica desse tipo de política é não levar em consideração os recursos limitados;

2- Redistributivas ou Arena: enquadram-se nesse grupo, as políticas sociais universais como o sistema tributário, a seguridade social, a política monetária, dentre outras. Estas políticas estão mais próximas das classes sociais e seus impactos não seriam individuais.

3- Regulatórias: têm como objetivo normatizar serviços e equipamentos. É o caso da legislação trabalhista e do código de trânsito.

4- Constituintes ou Constitutivas: estabelecem regras e procedimentos para que outras políticas possam ser criadas.

“No Brasil, devido à grande concentração de riqueza, renda e propriedade, os aspectos distributivos ou redistributivos das políticas têm presença na agenda". (SOUZA, 2006, p.28).

Nesse contexto, tem-se que as políticas sociais surgiram no país com o início da industrialização, porém essas ações focavam e beneficiavam apenas as pessoas que possuíam trabalho formal, as quais representavam a minoria da população brasileira, predominantemente rural até o final da década de 70 (ZAMBA; KUJAWA, 2017).

Ainda nesse cenário, o acesso a políticas estava vinculado ao também acesso ao mercado de trabalho formal, configurando-se como formas “de regulação social forjadas por meio de políticas sociais, que apesar de sua diversidade, tinham como sentido essencial dar suporte ao mercado produtor desses serviços, e operador desses benefícios ${ }^{4} . "(C O H N, 2020$, p.132). Assim, o provimento de políticas públicas (com recorte social) passou a ser obrigação do Estado com a promulgação da nova Constituição Federal em 1988.

$\mathrm{Na}$ era Vargas tratava-se a questão social como uma questão de polícia; no período posterior, uma questão que seria resolvida via industrialização, e na fase desenvolvimentista, buscou-se a inclusão social via mercado através da geração de emprego (CONH, 2020). Acreditava-se assim que a desigualdade social seria resolvida quando o país atingisse um certo nível de desenvolvimento econômico, visto como

\footnotetext{
${ }^{4}$ No primeiro caso, por meio da compra de serviços privados para satisfação da demanda criada pelo Estado (exemplo, direito à assistência médica previdenciária por parte dos trabalhadores assalariados urbanos); no segundo, fomentando o mercado e a circulação de mercadorias via aumento da capacidade de consumo desses trabalhadores quando não mais aptos para o trabalho (CONH, 2020, p. 132).
} 
sinônimo de crescimento, uma perspectiva defasada de desenvolvimento, que nos deixou uma enorme dívida social.

A "constituição cidadã" como ficou popularmente conhecida, é considerada um marco na garantia dos direitos da população brasileira, ocorrendo uma reconfiguração do papel do Estado com novas formas de atuação na sociedade. No entanto, ela foi promulgada no período de ascensão do liberalismo econômico, fundamentado na concepção do Estado Mínimo, em um cenário de crise e endividamento público altíssimo, decorrente dos governos militares.

Dessa forma, só a partir da metade da década de 90, foram criadas algumas políticas públicas de recorte social como: o Benefício de Prestação Continuada (BPC); - Programa de Erradicação do Trabalho Infantil (PETI); o Bolsa Escola; a regulamentação do Sistema Único de Saúde; a construção da Leis de Diretrizes e Bases e a Lei Orgânica de Assistência Social (LOAS); políticas nas áreas da agricultura familiar; geração de emprego e qualificação do trabalhador (ZAMBA; KUJAWA, 2017; COHN, 2020).

O período posterior, especificamente os anos de 2003 e 2016, foi caracterizado, do ponto de vista político, pela permanência dos governos de esquerda no poder. Tendo início com o governo Lula, o qual segundo Conh (2020), radicalizou o investimento na área social, mas, apesar disso, as ações implementadas continuaram distributivas e não redistributivas.

Nessa conjutura destacamos a criação de programas nas áreas da educação, de transferência de renda, assistência social e estímulo ao crescimento, quais sejam: Programa Fome Zero (no primeiro ano do governo de Luís Inácio Lula da Silva); o Programa Bolsa Família; o Programa de Aceleração do Crescimento (PAC); o Programa Nacional de Acesso ao Ensino Técnico e ao Emprego (Pronatec); a Reestruturação e Expansão das Universidades Federais (Reuni); o Programa Universidade para Todos (ProUni); o programa Minha Casa Minha Vida; Programas destinados a agricultura familiar e na economia solidária, demarcação de terras indígenas, dentre outros. Assim, podemos afirmar que apesar das críticas direcionadas a atuação do governo nessas áreas, houve, nesse período, “[...] o fortalecimento da concepção de Estado compreendendo a sua responsabilidade social na garantia de direitos e na distribuição de renda, o que contribuiu para a significativa melhoria dos índices sociais". (ZAMBAM; KUJAWA, 2017). 
Aperfeiçoando a ideia da autora mencionada, ousamos afirmar que algumas políticas implementadas no período em questão, tiveram também um caráter redistributivo; contudo, apesar de acreditarmos que sim, não podemos afirmar aqui se elas promoveram ou não algum tipo de redistribuição na sociedade, para tanto seria necessário uma avaliação dos impactos dessas ações. Portanto, nos limitaremos a citar algumas das políticas implementadas nesse contexto: o Programa Nacional de Acesso ao Ensino Técnico e ao Emprego (Pronatec); a Reestruturação e Expansão das Universidades Federais (Reuni); o Programa Universidade para Todos (ProUni) dentre outros.

Em se tratando do ambiente macroeconômico, o governo Lula continuou com a política de manutenção de superávit primário para pagamento dos juros da dívida, metas de inflação e câmbio flutuante, configurando-se, de acordo alguns autores, em um neoliberalismo leve. Contudo, segundo Carleial (2015), apesar de o governo manter essas medidas, houve avanços significativos nas áreas econômicas e sociais no período, oriundos de ações como a valorização real do salário-mínimo associada ao crédito pessoal; programas de transferência de renda e criação do Microempreendedor Individual, atreladas aos gastos de investimentos em infraestrutura e nos setores de petróleo e gás.

A segunda fase correspondeu ao período de 2011 e 2015 com governo de Dilma Rousseff,

[...] a política econômica do primeiro governo Dilma Rousseff tinha atendido a várias das bandeiras defendidas pela FIESP ao longo dos anos, no que se chamaria de "nova matriz econômica": redução de taxas de juros e tarifas de energia elétrica; desonerações tributárias e crédito subsidiado; desvalorização cambial e protecionismo industrial seletivo; concessões de serviços públicos para a iniciativa privada. Algumas dessas iniciativas foram, inclusive, solicitadas em documento entregue ao governo e assinado em conjunto com outras organizações empresariais e centrais sindicais em 2011 (BASTOS, 2017, p.63).

A segunda fase do governo Dilma é marcada por uma enorme crise política decorrente da crise moral, que se alastra no país faz séculos, agravando-se com o ajuste fiscal e monetário abrupto, adotado pela presidente após a sua reeleição em 2014, contrariando o que foi prometido na campanha.

Com uma medida extrema de cortes de gastos no Valor de 70 bilhões de reais, impactando negativamente o mercado de trabalho, aumentando o desemprego e o andamento das políticas públicas nas áreas sociais, principalmente na saúde e 
educação, que sofreram corte de gastos, os quais provocaram: suspensão de bolsas de pós-graduação, atraso na transferência de verbas para as universidades e nos recursos do FIES, PRONATEC, Programa Ciências Sem Fronteiras e Farmácia Popular (CARLEIAL, 2015).

Medidas estas, consideradas por alguns autores como neoliberais extremas, que deram início ao enfraquecimento da frágil rede de proteção social conquistada a partir da Constituição de 1988. Atrelado a esses fatores, surgiram os escândalos de corrupção na Petrobrás, envolvendo grandes empreiteiras, tornando mais grave, a situação do governo, que sofreu um impeachment em 2016.

Com a saída de Dilma, assume o governo, Michel Temer (2016/2018), seu vice, o qual adota um ajuste fiscal nos moldes da "versão mais "cruel" do neoliberalismo com projetos de privatização; desregulamentação de direitos sociais, trabalhistas e cortes de gastos nas áreas sociais, iniciando com as Reformas pós impeachment.

\section{Emendas Constitucionais 95/2016, 106/2020 e 109/2021, suas relações com o endividamento público e impacto nas políticas sociais}

No ano de 2016 foi aprovada a EC 95/2016, instituindo um “novo" regime fiscal e sem um diálogo com a sociedade, apesar dos protestos contra a aprovação dessa emenda terem alcançado espaço nas mídias por esta afetar a maioria das políticas públicas federais.

Assim foi adotada uma medida de congelamento das despesas primárias em termos reais, tendo como base o ano de 2016, o exercício desse ano demarcaria o limite de gastos pelos próximos dez anos de todos os poderes da União, do Ministério Público da União (MPU) e da Defensoria Pública da União (DPU), sendo admitida apenas a atualização monetária pelo índice de preço ao consumidor Amplo IPCA.

Dessa forma, as despesas primárias seriam decrescentes, e em um contexto de crescimento econômico representam fatias decrescentes do Produto Interno Bruto (PIB), não sendo, portanto, permitido aumentar os investimentos em um setor, sem antes fazer cortes em outro (MARIANO, 2017).

Assim qual a relação da EC 95/2016 com a dívida pública? Nesse enquadramento, segundo consta no Relatório Anual da Dívida, elaborado pelo Tesouro Nacional em 2016, o país teve queda na arrecadação, tendo, portanto, uma necessidade líquida de financiamento no valor de $\mathrm{R} \$ 666,20$ bilhões, aumentando a 
Dívida Bruta do Governo Geral, que passou de 65,1\% do PIB em 2015 para 70,5\% em 2016 com os títulos públicos apresentando alta volatilidade.

Dessa forma, a gestão da dívida utilizou como estratégia para gerir a dívida interna: o aumento da participação dos títulos remunerados a taxas flutuantes; a realização de leilões extraordinários de recompra de títulos públicos, devido a alta volatilidade, objetivando o bom funcionamento do mercado; e a realização de leilões de troca de títulos, visando ao alongamento do perfil da dívida interna (RELATÓRIO ANUAL DA DÍVIDA PÚBLICA, 2016). Com relação a dívida externa, houve duas emissões no mercado externo; realização de compra de moeda estrangeira para pagamento de dívidas de curto e médio prazo; realização de resgate antecipado dentre outros fatores, que possibilitaram o interesse dos investidores pelos ativos brasileiros e uma melhora nas expectativas destes, com relação ao cenário político e econômico do país (RELATÓRIO ANUAL DA DÍVIDA PÚBLICA, 2016).

Porém, essa expectativa limitou-se aos investidores do mercado financeiro e aos grandes empresários, os quais vibraram com as reformas governamentais no período, porque a população, especificamente as classes mais humildes, que necessitam dos serviços públicos, assistiram/assistem a uma enorme precarização do que já era insuficiente ao atendimento de suas demandas.

Para Mariano (2017), a EC 95/2016 suspende o projeto constitucional e opta por uma antidemocracia econômica em prol dos credores da dívida pública.

Essa lógica pode ser observada pelo $\S 6^{\circ}$ desse mesmo artigo 102 do $\mathrm{ADCT}^{5}$, que estabeleceu ficarem excluídos do teto: I - as transferências constitucionais relativas à: a) participação dos Estados e Municípios no produto da exploração de petróleo e gás natural; b) repartição das receitas tributárias; c) cotas estaduais e municipais da contribuição social do salário-educação; d) as despesas relativas aos serviços da polícia civil, polícia militar, bombeiros e demais serviços públicos do Distrito Federal; e) e a complementação das cotas do salário-educação do DF e Estados caso o número de alunos não atinja o limite necessário; II - os créditos extraordinários abertos para atender a despesas imprevisíveis e urgentes, como as decorrentes de guerra, comoção interna ou calamidade pública; III - despesas com a realização de eleições pela justiça eleitoral; IV- outras transferências obrigatórias derivadas de lei que sejam apuradas em função de receitas vinculadas; e $\mathrm{V}$ - despesas com aumento de capital de empresas estatais não dependentes (MARIANO, 2017, p. 263).

5 Ato das Disposições Constitucionais Transitórias. 
A autora enfatiza o item III: "as despesas com o aumento de capital de empresas estatais não dependentes", empresas públicas que não precisam de recursos da união para se manterem, por ser tratar de uma medida, que contribui com o crescimento da dívida pública, oferecendo garantias a estas empresas na emissão de debêntures, que não serão vendidas publicamente, mas a determinados investidores, os quais pagarão um valor muito inferior (12,5\% de valor de face) aos juros que receberão (até 23\%). Possibilitando assim que esses investidores retirem os investimentos realizados no primeiro ano, bem como a acumulação de prejuízos por essas empresas estatais, as quais necessitarão de recursos públicos (retirados das áreas sociais) para cobrir tais prejuízos (MARIANO, 2017).

É importante mencionarmos também que essa medida contribui com o discurso de privatização destas empresas com a justificativa de que estão dando prejuízos aos cofres públicos, levando parte da sociedade a defender os projetos de privatização, consistindo, portanto, em um esquema financeiro com o intuito de atender como sempre ao capital financeiro, em detrimento das demandas mais essenciais da população brasileira, que vem sendo privada de exercer as suas liberdades substantivas essenciais, mesmo sem perceber por vivermos em um "Estado Democrático".

As liberdades substantivas essenciais: liberdades políticas; facilidades econômicas; oportunidades sociais (boa saúde, educação básica, incentivos etc.); garantias de transparência e segurança protetora, são apontadas por Sen (2000) como os principais fins e meios do desenvolvimento de uma sociedade. Significando que a viabilização destas liberdades pelo Estado via políticas públicas, promove as liberdades individuais.

Contudo, engana-se quem acredita que a "proteção" ao mercado financeiro via endividamento público, ou, a "impunidade da dívida pública”, segundo alguns autores, teve início com a aprovação da EC 95/2016. Na Constituição Federal tem-se o Art. 192, que institui o Sistema Financeiro Nacional, visando ao atendimento dos interesses da coletividade.

Art. 192. O sistema financeiro nacional, estruturado de forma a promover o desenvolvimento equilibrado do País e a servir aos interesses da coletividade, em todas as partes que o compõem, abrangendo as cooperativas de crédito, será regulado por leis complementares que disporão, inclusive, sobre a participação do 
capital estrangeiro nas instituições que o integram. (EC n o 13/96 e EC n o 40/2003) I - (Revogado); II - (Revogado); III - (Revogado):a) (Revogada);b) (Revogada);IV - (Revogado);V - (Revogado);VI (Revogado);VII - (Revogado); VIII - (Revogado).§ $1^{\circ}$ (Revogado) § 2 (Revogado)§ $3^{\circ}$ (Revogado) (BRASIL, 1988, p.114-115).

Porém, o que temos visto, "de maneira regulamentada", e denominado por Zaneti (2017) é "desconstitucionalização" do sistema financeiro, que está muito distante de atender e ou servir aos interesses da coletividade promovendo um desenvolvimento equilibrado na sociedade brasileira.

Dércio Garcia Munhoz (2017), no prefácio do livro "O Complô: como o sistema financeiro e seus agentes políticos sequestraram a economia brasileira" de Hermes Zaneti (mencionado no parágrafo anterior) afirma que as regulamentações direcionadas as operações do sistema financeiro, propostas por alguns constituintes, foram alvo de uma reação organizada do sistema bancário. Como foi o caso da tentativa de limitar a taxa de juros reais a $12 \%$ a.a , que devido a pressão sofrida pelos bancos foi banida pelo Congresso Nacional, consistindo, segundo o autor, no passo inicial para posteriores ações em benefício do mercado financeiro.

A primeira delas foi a proibição do Banco Central de emitir títulos próprios para a execução da política monetária, que culminou na criação das operações de Open Market, um instrumento de política monetária do $\mathrm{BC}$ realizado com títulos do tesouro, com os quais, o Banco Central não se preocupa com os custos. Assim, as despesas com os juros dessas operações não passam pela contabilidade do BC, pois são classificadas como custos e, dessa forma, os encargos financeiros da política monetária e da dívida pública não são distinguidos, evitando-se assim, segundo o autor, uma discussão política sobre o assunto, deixando-o longe do conhecimento da sociedade.

Portanto, quando o endividamento público aumenta demasiadamente, responsabiliza-se algumas áreas, como foi o caso recente da previdência social, buscando-se a solução nas reformas governamentais, via retirada de direitos sociais e trabalhistas, impossibilitando assim, a criação e manutenção de políticas públicas essenciais à expansão das liberdades individuais.

Vale salientar, ainda no contexto do Governo Temer, a aprovação da Reforma Trabalhista em 2017, que flexibilizou os direitos trabalhistas consolidados pela Consolidação das Leis do Trabalho (CLT) em 1943, e desregulamentou as relações entre empregador e empregado, e o envio da proposta de Reforma da previdência ao 
senado, as quais não serão descritas aqui por fugir do nosso objetivo.

Nesse cenário de "abate das políticas sociais”, termo utilizado por Conh (2020), outro fator que veio "somar”, é o que denominaremos aqui como: “desconstrução cognitiva", que eclodiu e se alastrou na sociedade, de uma maneira estarrecedora nos últimos anos, dificultando ainda mais a luta de alguns grupos por direitos.

Em meio a esse cenário caótico, no ano 2018, assume a presidência o militar reformado, Jair Messias Bolsonaro, utilizando um discurso agressivo, segregacionista e negacionista, com uma forte ofensiva contra os movimentos sociais, os indígenas, as mulheres, a população LGBTQ+, os negros, as Organizações não Governamentais (ONGs), as Universidades Públicas, os Institutos de Pesquisas, os órgãos ligados ao meio ambiente dentre outras instituições, que se mostrem contrária as "ideias" oriundas deste "governo". Assim, o discurso e as ações do atual governo, visam a uma destruição dos direitos sociais, da economia, do meio ambiente, da democracia e, principalmente, do conhecimento, sendo esse o mais grave porque a sua falta leva a todos os fatos mencionados anteriormente.

Para tanto, o governo inicia com a aprovação da reforma da previdência, e “elege” as universidades públicas como o principal foco desse "processo destrutivo", as quais já vinham sofrendo com o corte de recursos após aprovação da EC/95 2016. Porém, na atual gestão, a questão ultrapassou os cortes de gastos e as universidades são vistas pelo presidente e boa parte dos membros do governo, como propagadoras do “comunismo". Porém, merece destaque também, nesse contexto obscurantista, o ataque ao Instituto Brasileiro do Meio Ambiente (IBAMA), ao Instituto Nacional de Pesquisas Espaciais (INPE), o ataque a imprensa dentre outros. Portanto, essas ações e falas negacionistas interferem no tímido aparato de proteção social, que vinha sendo construído após a constituição de 1988. Configurando-se assim, no rompimento de "qualquer forma de solidariedade social, mesmo aquela neoliberal de focalização das políticas sociais aos segmentos extremamente pobres da população”. (COHN, 2020, p. 26).

Ainda sobre o cenário destacado acima, surge a pandemia do coronavírus no ano de 2020 acentuando ainda mais a crise moral, política e econômica do país, culminando assim, em uma crise sanitária, que foi agravada pela incapacidade do governo de gerir e prestar assistência a população, por meio da utilização de discursos negacionistas proferidos pelo presidente da república e sua equipe, os quais 
incentivaram parte da população a descumprir as medidas de isolamento recomendadas pela Organização Mundial de Saúde.

Assim, devido ao Estado de Calamidade Pública foi aprovada a Emenda Constitucional 106/2020, instituindo o regime fiscal, financeiro e de contratações de calamidade pública. Porém, essa emenda foi bastante criticada por alguns estudiosos, por representar mais uma forma de aumentar o endividamento público, utilizando como desculpa amenizar os problemas surgidos com a pandemia.

Foi estabelecido que “A União adotará regime extraordinário fiscal, financeiro e de contratações para atender às necessidades dele decorrentes, somente naquilo em que a urgência for incompatível com o regime regular, nos termos desta Emenda Constitucional". (BRASIL, 2020, p.03). No entanto, os artigos $4^{\circ}, 6^{\circ}$ e $7^{\circ}$ da emenda em questão, fundamentam essas críticas, por ensejarem transações de cunho financeiro, que não têm relação com o combate a pandemia, configurando-se em práticas realizadas pelo Banco Central que promovem o aumento da dívida pública, utilizando, portanto, o contexto da pandemia e seus efeitos para outras finalidades.

De acordo com Santiago (2020), a emenda promove os interesses financeiros dos investidores em títulos públicos (donos do capital), os quais recebem juros sem aumentar a atividade produtiva e sem gerar emprego, beneficiando-se com os recursos que deveriam ser destinados ao combate a pandemia, e para a assistência a parte mais fragilizada da população. 0 mesmo autor sublinha que essa emenda prejudica ainda as gerações futuras porque será exigido cada vez mais cortes de gastos, impactando as políticas sociais e os investimentos nos setores produtivos.

Dessa forma, no final do ano de 2020 assiste-se a um aumento considerável da dívida bruta, que alcançou $89,2 \%$ do PIB. Assim, o governo adotou como estratégia para o financiamento da dívida: a redução dos prazos dos títulos ofertados pelo Tesouro Nacional, promovendo assim, uma maior concentração da dívida no curto prazo, que manteve-se predominantemente doméstica; além disso, é importante destacarmos, que houve nesse período, a contratação de empréstimos com organismos multilaterais, que serão utilizados para o pagamento da dívida obtida via emissão de títulos, em decorrência dos “vários” programas de mitigação dos efeitos econômicos e sociais da pandemia (RELATÓRIO ANUAL DA DÍVIDA, 2020).

Portanto, de acordo com Mendes (2021), apesar da gravidade da situação sanitária, social e econômica que se encontra o país, temos uma classe política 
incapaz de criar um consenso mínimo, sobre como alocar, no presente e no futuro, os custos fiscais do enfrentamento da calamidade.

Assim dando prosseguimento ao processo de endividamento desenfreado em nome da amenização dos efeitos causado pela pandemia, em março de 2021 foi aprovada a Emenda Constitucional 109, possuindo dois objetivos explícitos: pagamento do auxílio emergencial no ano de 2021 e criação de instrumentos de ajustes fiscal futuro. Essa medida, assim como as outras mencionadas, adotou medidas que penalizam a criação e a manutenção de programas públicos fundamentais no atual contexto brasileiro, que clama por políticas assistenciais, compensatórias, desenvolvimentistas e econômicas de cunho expansionista, apesar de sua aprovação ser justificada, pela necessidade de pagamento do auxílio emergencial no ano de 2021.

Nesse sentido, Mendes (2021) descreve os principais pontos da PEC em questão, demonstrando os seus impactos, principalmente para as futuras gerações, que pagará os custos, não tendo suas perspectivas educacionais, de renda etc. atendidas. Essa medida de combate a pandemia não apresenta mecanismos que aloquem os gastos entre os diversos setores da sociedade focando apenas no aumento do endividamento público. 0 autor analisa e classifica as medidas adotadas da seguinte maneira:

- Medidas de Impacto Direto a União: desobrigação de financiamento para os estados e municípios pagarem seus precatórios, afastando, assim, o risco de perda financeira do tesouro nacional; revogação da obrigação constitucional de criação de transferências para estados e municípios e a desvinculação de superávit financeiro de fundos;

- Medidas de Impacto Futuro para a União (gatilho do teto de gastos): alteração do mecanismo para contenção das despesas obrigatórias descrito na EC 95/2016. Essa medida impacta o contexto das políticas públicas, visto que "limitar o crescimento de uma parte da despesa de modo que ela cresça abaixo da inflação significa abrir espaço no teto dos anos seguintes para realizar mais despesas não-obrigatórias". (MENDES, 2021, p.9-10). Evitando, segundo o autor, que, essas últimas não sejam excessivamente comprimidas ao longo do tempo.

Com essa alteração do mecanismo de contenção das despesas obrigatórias no 
presente, a emenda em questão possibilita que se gaste com o pagamento das despesas da dívida mobiliária e contratual consideradas pela Escola Nacional de Administração Pública- ENAP (2014), uma das despesas obrigatórias principais na elaboração dos orçamentos da União. Prejudicando assim a realização de despesas não obrigatórias, ou seja, aquelas que o governo tem liberdade de decidir, como é o caso dos investimentos em infraestrutura, financiamento de pesquisas e diversas políticas públicas fundamentais á expansão das capacidades das pessoas.

- Medida não-crível: redução de benefícios tributários da União. 0 autor considera que essa medida não será adotada pelo fato de se restringir apenas ao envio de uma proposta pelo Presidente da república ao Congresso, o qual não tem nenhuma obrigação de aprová-la ou apreciá-la.

- Medidas direcionadas aos estados e municípios: destaca-se a criação de gatilhos de contenção de despesas obrigatórias, neste caso "o gatilho disparará quando a despesa corrente estiver igual ou superior a 95\% da receita corrente". (MENDES, 2021, p.15).

- Medidas de caráter principiológico: refletem princípios gerais de finanças e gestão pública. Neste caso específico foi o de promover a avaliação das políticas públicas, uma medida que consta na EC 109/2021. Para Mendes (2021), a sua presença na emenda pode impulsionar essa agenda, mas não necessariamente isso pode se concretizar.

Acrescentaremos aqui a importância da avaliação das políticas públicas para a sociedade, porém vale ressaltar que esta avaliação deve abranger questões quantitativas e qualitativas, relacionadas a eficiência, eficácia e efetividade, que busca avaliar o impacto destas para a população-alvo. Porém, sendo esta uma obrigatoriedade constitucional, ela poderá ser utilizada positivamente como pensa Mendes (2021), ou de maneira negativa como uma forma de perseguição e desmonte das políticas de recorte social, atendendo aos preceitos neoliberais. Outra medida de caráter principiológico, consistiu no estabelecimento de que a União, os Estados e Municípios conduzam suas políticas fiscais de maneira a manter a dívida pública em nível sustentável.

O autor considera que essas medidas não serão cumpridas na prática e, "estão 
preparando o terreno para, no futuro, substituir as atuais regras fiscais constitucionais (teto de gastos e regra de ouro) por um sistema baseado na sustentabilidade da dívida”. (MENDES, 2021 p. 17).

- A autorização para gasto extraordinário com o auxílio emergencial: Foi estipulado o valor de $\mathrm{R} \$ 44$ bilhões acima do teto de gastos, não sendo computado este valor para obediência da regra de ouro; da meta de resultado primário e também não está sujeita a regra de criação de despesa da Lei de Responsabilidade Fiscal, ainda permite que "o crédito orçamentário seja extraordinário afastando a exigência de “imprevisibilidade" da despesa." (MENDES, 2021 p. 17).

Vemos que o Estado brasileiro está muito longe de atender os direitos constitucionais via implementação de políticas sociais e desenvolvimentistas, que promovam melhorias na vida das pessoas, ou, segundo a concepção de desenvolvimento como liberdade de Sen, que "promovam a expansão das liberdades individuais", visto que a classe política está “comprometida” com o atendimento das necessidades do mercado financeiro, e, muito distante de formular políticas que atendam as necessidades da população em geral.

Como destaca Gonçalves e Pomar (2001), para construir um mundo sem desigualdades ou, pelo menos um mundo no qual ela seja reduzida, é necessária a subversão dos fundamentos econômicos e a inversão do fluxo dos recursos mundiais dos ricos para os pobres.

\section{Considerações Finais}

Nosso objetivo principal objetivo foi refletir sobre a aprovação das Emendas Constitucionais 95/2016, 106/2020 e 109/2021 e suas relações com o endividamento público recente, em detrimento do investimento em políticas de recorte social no Brasil, em um contexto no qual a população clama por ações governamentais.

Portanto, verificar que a aprovação destas emendas constitucionais traduz-se em mais uma "maneira legal" de atender aos interesses do mercado financeiro, por meio do endividamento da população brasileira, é estarrecedor para nós que estudamos políticas públicas, e, assim o seria para a população em geral, se esta tivesse conhecimento desse processo.

Como vimos ao longo do desenvolvimento do trabalho, o investimento nas áreas 
sociais no Brasil vêm sendo subordinado às questões econômicas, prevalecendo a crença de que o crescimento, embutido em uma concepção de desenvolvimento arcaica, que não deu certo, levaria a melhoria nas condições de vida das pessoas, resultando assim, no aumento no aumento da pobreza. Assim só a partir do ano 2000, o país assiste a uma maior preocupação com as políticas sociais, que passaram a ser a principal propaganda do governo Lula, havendo, nesse período, a criação e implementação de vários programas apesar de o governo continuar neoliberal do ponto de vista macroeconômico. Porém, em decorrência de fatores econômicos internacionais, macroeconômicos nacionais e políticos, esse cenário começa a ser invertido a partir de 2015, no governo Dilma, com a adoção de políticas fiscais restritivas, aumentando em 2016 com a aprovação da reforma trabalhista e da EC 95, chegando ao ápice nos dois últimos anos com a aprovação das emendas 106/2020 e $109 / 2021$.

Foram incluídas nessas emendas constitucionais algumas medidas para beneficiar o mercado financeiro, promovendo a elevação do endividamento público, socializando os custos deste com as gerações atuais e futuras, que sofrerão ainda mais com a redução no atendimento de seus direitos a educação, saúde, moradia, previdência social dentre outros descritos na Constituição Federal, devido a necessidade de contenção de "gastos públicos" para o pagamento dos custos da dívida. 0 que nos leva a concluir que o Brasil ainda está muito aquém no que se refere ao atendimento das demandas da população mais carente, isso só poderá acontecer se houver uma inversão no fluxo dos recursos, que atualmente flui dos pobres e miseráveis para os ricos.

\section{Referências}

BASTOS, P. P.Z. Ascensão e Crise do Governo Dilma Rousseff e o Golpe de 2016: Poder Estrutural, Contradição e Ideologia. Revista de Economia Contemporânea. Rio de Janeiro Núm. esp. 63p. 2017. Disponível em: https: / /www.scielo.br/j/rec/a/Q64JZq7tHnKDsYGVRrYS4mD/?format=pdf\&lang=pt. Acesso em: 07/06/2021.

BRASIL. Senado Federal. Proposta de Emenda à Constituição no 106, de 2020. Institui regime extraordinário fiscal, financeiro e de contratações para enfrentamento de calamidade pública nacional decorrente de pandemia. Brasília, DF: Senado $2020 . \quad$ Federal, Disponível 
http://www.planalto.gov.br/ccivil_03/constituicao/emendas/emc/emc106.htm.

Acesso em: 05/06/2021.

BOSCHETTI, Ivanete. Avaliação de políticas, programas e projetos sociais: In: Serviço Social: Direitos Sociais e Competências Profissionais. Brasília: CFESS/ABEPSS, 2009. BRASIL. Constituição (1988). Constituição da República Federativa do Brasil. Brasília, DF: Senado Federal: Centro Gráfico, 1988. Disponível em: https: //www2.senado.leg.br/bdsf/bitstream/handle/id/518231/CF88_Livro_EC91_201 6.pdf. Acesso em : 20 de Maio de 1979.

CARLEIAL, L. M. da F. Política econômica, mercado de trabalho e democracia: o segundo governo Dilma Rousseff. Estud. av., São Paulo, v. 29, n.85, pág.201-214, dezembro de 2015.2 Disponível em <http:/ / www.scielo.br/scielo.php?script=sci_arttext\&pid=S0103-

$40142015000300014 \& \operatorname{lng}=e n \& n r m=i s o>$. Acesso em 20 de outubro de 2020.

COHN, A. As Políticas de Abate Social no Brasil Contemporâneo. Lua Nova, São Paulo, n.109, pág.129-160, abril de 2020.Disponível em: http: //www.scielo.br/scielo.php?script=sci_arttext\&pid=S0102-

64452020000100129\&lng=en\&nrm=iso. Acesso em 20 de outubro de 2020.

ENAP (2014) Escola Nacional de Administração Pública. Orçamento Público: Conceitos Básicos. Brasília, 2014. Disponível em: https://repositorio.enap.gov.br/bitstream. Acesso em: 21/05/2021.

GONÇALVES, R.POMAR, V. O Brasil endividado: Como nossa dívida externa aumentou mais de 100 bilhões de dólares nos anos 90. São Paulo: Fundação Perseu Abramo, 2001.Disponível em: https://fpabramo.org.br/publicacoes/estante/brasil-endividadoo-como-a-divida-externa-aumentou-mais-de-us-100-bilhoes-nos-anos-90/. Acesso em: 20 de Março de 2021.

MARIANO, C.M . Emenda constitucional 95/2016 e o teto dos gastos públicos: Brasil de volta ao estado de exceção econômico e ao capitalismo do desastre. Revista de Investigações Constitucionais. Curitiba,Vol. 4 . n.1. p.260-281 janeiro/abril 2017.Disponível em: https://revistas.ufpr.br/rinc/article/view/50289. Acesso em: 30 de Abril de 2021.

MENDES, M. Emenda Constitucional 109 (PEC Emergencial): a fragilidade e a incerteza fiscal permanecem. Instituto de Ensino e Pesquisa-Insper, Março, 2021. Disponível em: https://www.in.gov.br/en/web/dou/-/emenda-constitucional-n-109308527609. Acesso em: 30 de Março de 2021.

MENY, Ives; THOENIG, Jean-Claude. Las Políticas Públicas. Barcelona, Espanha: ARIEL, 1992.

MINISTÉRIO DA FAZENDA. Secretaria do Tesouro Nacional. Relatório anual da dívida pública. Brasília: MF, jan. 2017.

MINISTÉRIO DA FAZENDA. Secretaria do Tesouro Nacional. Relatório anual da dívida pública. Brasília: MF, jan. 2021.

SANTIAGO, P. R. Um crime chamado EC 10. Diário de Pernambuco, Recife, Julho.2020.Disponível

em:https://www.diariodepernambuco.com.br/noticia/opiniao/2020/07/um-crimechamado-ec-106.html. Acesso em: 05 de Maio de 2021.

SEN, Amartya. Desenvolvimento como liberdade. São Paulo: Companhia das Letras, 2010.

SOUZA, C. "Políticas Públicas: uma revisão da literatura". Sociologias, Porto Alegre, ano 8, $\mathrm{n}^{\circ}$ 16, jul/dez 2006, p. 20-45.

ZAMBAM, N. J.; KUJAWA, H., A. As políticas públicas em Amartya Sen: condição de agente e liberdade socialRevista Brasileira de Direito, Passo Fundo, v. 13, n.1, p.60- 
85 ,

mar.

2017.

Disponível

em:https://seer.imed.edu.br/index.php/revistadedireito/article/view/1486. Acesso em: 07 set. 2020.

ZANETI, H. O Complô: como o sistema financeiro e seus agentes políticos sequestraram a economia brasileira. Brasília: Verbena, 2017. 280p. Disponível em: https://auditoriacidada.org.br/livros/. Acesso em: 10 de Maio de 2021.

Recebido: 01 jun 2021 Aceito: 22 jun 2021 